\title{
Regional Lung Function in
}

\section{Patients with Bronchial Asthma}

\author{
T. Heckscher, H. Bass, A. Oriol, B. Rose, N. R. ANthonisen, and \\ D. V. BATES
} From the Joint Cardiorespiratory Service and the Division of Allergy and
Immunology Research, McGill University Clinic, Royal Victoria Hospital,
Montreal, Canada

A BSTRACT The regional distribution of pulmonary ventilation and perfusion and regional alveolar ventilation/perfusion ratios were measured with radioactive xenon ( ${ }^{\mathbf{1 3 3}}$ xenon) in 10 patients with asthma in remission. Four subjects had normal ventilation distribution, four had hypoventilation in some regions and normal ventilation in others, and two patients had abnormal ventilation in almost all lung regions. The lung bases were involved most frequently and the middle zones least frequently. Correlation was good between the degree of over-all ventilatory impairment calculated from ${ }^{133}$ xenon values and measurement of the maximal midexpiratory flow rate the same day.

Regions which were hypoventilated had low ventilation/perfusion ratios and also tended to be hypoperfused. In the eight subjects who had been studied similarly $5 \mathrm{yr}$ previously, changes in regional function correlated in general with changes in over-all function.

\section{INTRODUCTION}

Pulmonary ventilation sometimes is unevenly distributed in patients with spasmodic asthma, even during symptom-free intervals (1). Studies with

Dr. Heckscher is a fellow, World Health Organization. Dr. Bass is a postdoctoral fellow, National Heart Institute, U. S. Public Health Service. Dr. Anthonisen is a scholar of the Medical Research Council of Canada.

Address requests for reprints to Dr. N. R. Anthonisen, Joint Cardiorespiratory Service, Royal Victoria Hospital, Montreal 2, Canada.

Received for publication 9 August 1967 and in revised form 14 November 1967.
${ }^{133}$ xenon $\left({ }^{133} \mathrm{Xe}\right)$ in this laboratory (2) showed hypoventilation of lung regions in symptom-free patients with asthma, and it was concluded that these regions probably had low ventilation/perfusion ratios $\left(\dot{\mathrm{V}}_{\mathrm{A}} / \dot{\mathrm{Q}}\right)$. This conclusion was supported by the findings of Ledbetter, Bruck, and Farhi (3), who measured nitrogen tension in both alveolar gas and arterial blood in patients with asthma and found lung units with abnormally low alveolar $\dot{\mathrm{V}}_{\mathrm{A}} / \dot{\mathrm{Q}}$.

Recently developed ${ }^{133}$ xenon techniques were used in the present investigation of 10 patients whose asthma was "in remission." The aims were to document further the phenomenon of regional hypoventilation and to correlate it with tests of over-all pulmonary function; to detect regions with low $\dot{\mathrm{V}}_{\mathrm{A}} / \dot{\mathrm{Q}}$; to assess regional blood flow distribution; and, since most of these patients had been studied previously with ${ }^{133} \mathrm{Xe}(2)$, to record changes in regional function.

\section{METHODS}

Selection of patients. The subjects were two women and eight men, ranging in age from 21 to 51, with a mean of $36 \mathrm{yr}$, who were selected by one of us (B.R.) on the basis of the following criteria. All had been observed for several years and gave a history of recurrent episodes of bronchospasm, not necessarily related to respiratory infection. None had cough or produced sputum between episodes, and all thought they were physically fit at the time of study. All were on desensitization programs with vaccines; five were taking bronchodilator substance, and one was taking corticosteroids at the time of study.

Routine pulmonary function tests. Routine pulmonary function tests and the ${ }^{135} \mathrm{Xe}$ study were performed the same day. The maximal midexpiratory flow rate 
(MMFR) and forced expiratory volume [FEV (4)] were measured and were compared with predicted normal values $(4 a)$. We measured the functional residual capacity (FRC) while the patient was supine using the helium-dilution method.

Cardiac output. Cardiac output was measured by dyedilution techniques several times during each ${ }^{133} \mathrm{Xe}$ study. In four patients, Indocyanine green dye was used, and arterial blood was sampled to inscribe the dye curve. In six patients, Coomassie blue dye was used, and the curve was recorded as described in previous communications from this laboratory $(5,6)$. Cardiac output was calculated from dye curves by the Hamilton method. Intravenous dye injections were made through catheters placed in the superior vena cava, the subclavian vein, or the axillary vein.

Xenon techniques. These techniques have been described in detail in previous papers (7-9) and are briefly reviewed here. The patients were studied in the supine position with five collimated scintillation counters behind each lung. Under these circumstances, there are normally no regional differences in function as measured with ${ }^{133} \mathrm{Xe}$. The patient wore nose clips and breathed through a rubber mouthpiece that could be connected to an open or closed breathing circuit. The closed circuit consisted of a spirometer with mixing motor, $\mathrm{O}_{2}$ inlet, $\mathrm{CO}_{2}$ absorber, and a scintillation counter in the inspiratory line. The open circuit contained a dry gas meter in the inspiratory line; this device potentiometrically recorded inspired ventilation. The expiratory line contained a baffle box and a scintillation counter which monitored mixed expired ${ }^{13} \mathrm{Xe}$ concentrations. Each experiment consisted of three separate parts: (a) 5-10 min intravenous infusion of ${ }^{133} \mathrm{Xe}$ at a consțant rate of $1.0-1.5 \mathrm{mc} /$ min while the patient breathed from the open circuit, $(b)$ 5-10 min of ${ }^{138} \mathrm{Xe}$ rebreathing from the closed circuit, and (c) two i.v. bolus injections of the isotopes while the subject held his breath at FRC. The outputs of the scintillation counters were digitally recorded on magnetic tape which was played back through rate meters and recorded (9).

Calculations. Regional intrapulmonary count rates were calculated by subtracting count rates due to chest wall radiation from over-all count rates. Background count rates from the chest wall during infusion and rebreathing were assumed to be the same as those recorded after completion of ${ }^{133} \mathrm{Xe}$ washout or $20-30 \mathrm{~min}$ after administration of ${ }^{138} \mathrm{Xe}$ had ceased. This approach necessarily underestimates chest wall count rates, but our findings in patients who have undergone pneumonectomy show this error to be small. 1

Regional ventilation. Regional ventilation per unit lung gas volume was estimated twice in each region in nine patients by observation of regional washout once after the isotope had been rebreathed and once after it had been infused; it was estimated after infusion only in patient W. A. To facilitate observation, at the end of infusion the i.v.

1 N. R. Anthonisen, H. Bass, and A. Oriol. Unpublished data. catheter was flushed rapidly with saline. The time necessary for intrapulmonary count rates to reach one-half their initial, prewashout values $\left(\mathrm{t}_{\frac{1}{3}}\right)$ was measured in minutes. $t_{k}$, which is reciprocally related to ventilation per unit volume, was standardized:

$$
\tilde{\mathrm{V}}=1 / \mathrm{t}_{\frac{1}{2}} \times \mathrm{FRC} / \dot{V}_{\mathrm{I}} \times 100
$$

where $\dot{V} I$ represents inspired minute ventilation during washout. Thus, $\tilde{V}$ is a dimensionless index of regional ventilation. On the basis of findings in normal subjects, regional $\tilde{\mathrm{V}}<50$ was defined as abnormal, and between 50 and 60 was defined as borderline. ${ }^{2} t_{1}$ was used as the basic measurement because more detailed analysis of regional washout is increasingly inaccurate (10).

Regional $\dot{V} \mathrm{~A} / \dot{Q}$. Regional $\dot{\mathrm{V}}_{\mathrm{A}} / \dot{Q}$ was determined as $\mathrm{U}_{\mathbf{i}} \cdot \mathrm{C}_{\tilde{\mathrm{i}}} / \mathrm{U}_{\mathbf{p}} \cdot \mathrm{F}_{\mathbf{I}}=\dot{\mathrm{V}}_{\mathrm{A}} / \dot{Q}$, where $\mathrm{U}_{\mathbf{i}}$ is regional count rate during rebreathing, $U_{p}$ is regional count rate during infusion, $\mathrm{F}_{\mathrm{I}}$ is inspired ${ }^{133} \mathrm{Xe}$ concentration during rebreathing, and $\mathrm{C}_{\overline{\mathrm{v}}}$ is mixed venous concentration during infusion. $\mathrm{C}_{\bar{v}}$ was calculated by dividing the ${ }^{133} \mathrm{Xe}$ injection rate by the cardiac output. The above relationship is based on the assumption that regional pulmonary ${ }^{133} \mathrm{Xe}$ exchange attains steady-state conditions during both infusion and rebreathing (7). We have not defined regions as normal or abnormal on the basis of their $\dot{\mathrm{V}}_{\mathrm{A}} / \dot{\mathrm{Q}}$, preferring to use regional washout as the decisive measurement. It is worth noting, however, that in normal subjects regional $\dot{V}_{A} / \dot{Q}$ as measured by this technique is often less than the commonly accepted normal values of $0.8-1.0$, and may be as low as 0.60 . Though this value could be due to error it may also be related to the position of our subjects. Over-all $\dot{V}_{A} / \dot{Q}$ is lower in the supine position than in the erect; cardiac output increases (11) and alveolar ventilation decreases (12) with tilt from erect to supine position. It is possible then that our finding of $\dot{V}_{A} / \dot{Q}$ in the vicinity of 0.60 in normal regions is a valid one. ${ }^{3}$

Perfusion distribution. Perfusion indices ( $\dot{Q}_{\mathrm{I}} \mathrm{I}$ ) were calculated as outlined by Ball, Stewart, Newsham, and

${ }^{2}$ Theoretically, normal values for $\tilde{\mathrm{V}}$ should be about 100 . If lung regions were homogeneous, $t_{\text {w }}$ would relate to regional ventilation per unit volume $\left(\dot{\mathrm{V}}_{\mathbf{A}} / \mathrm{VA}_{\mathrm{A}}\right)$, as follows:

$$
\dot{\mathrm{V}}_{\mathrm{A}} / \mathrm{VA}=\frac{\ln 2}{\mathrm{t}_{\mathrm{z}}}=\frac{0.693}{\mathrm{t}_{\mathrm{t}}}
$$

Over-all alveolar ventilation equals approximately $70 \%$ of total ventilation $\left(\dot{V}_{I}\right)$, so that in calculating $\tilde{V}$ the numerical constants cancel each other. Though it is not uncommon for the $\tilde{V}$ of normal regions to be $<100$, it is probably conservative to set the lower limit for normal at 60 , as we have done.

${ }^{3}$ The following relationship (13) serves to illustrate the above:

$$
\dot{\mathrm{V}}_{\mathrm{A}} / \dot{\mathrm{Q}}=\mathrm{R} .863 \frac{\left(\mathrm{CaO}_{2}-\mathrm{CvO}_{2}\right)}{\mathrm{PA}_{\mathrm{AO}_{2}}}
$$

where $\mathrm{R}$ is respiratory quotient, $\left(\mathrm{CaO}_{\mathrm{O} 2}-\mathrm{Cv}_{\mathrm{O} 2}\right)$ is the arteriovenous oxygen difference, and $\mathrm{PACO}_{2}$ the alveolar $\mathrm{CO}_{2}$ tension. If $\mathrm{R}=0.8, \mathrm{PACO}_{2}=42 \mathrm{~mm} \mathrm{Hg}$, and $\left(\mathrm{CaO}_{2}-\mathrm{CvO}_{2}\right)=40 \mathrm{ml} /$ liter, $\dot{\mathrm{V}}_{\mathrm{A}} / Q=0.66$. All of the above values are reasonable for supine subjects $(11,12)$. 
Bates (9). This calculation is based on the assumption that the rebreathing process proceeds to complete equilibration. However, in our calculation of regional $\dot{V}_{\mathbf{A}} / \dot{\mathbf{Q}}$ we assumed that the rebreathing procedure produced regional steady states. Regional ${ }^{133} \mathrm{Xe}$ exchange after 5-10 min of rebreathing has been described as (7):

$$
F_{I V A}=F_{A_{i}} \dot{V_{A}}-F_{A_{i} \alpha} \propto \dot{Q}
$$

where $\dot{V}_{A}$ is regional ventilation, $\dot{Q}$ is regional perfusion, and $\alpha$ is the solubility coefficient for ${ }^{133} \mathrm{Xe}$ (14). It can be seen that the presence of equilibration depends on $\alpha$, and given a solubility, on the size of $\dot{Q}$ in relation to $\dot{V} A$. At $\dot{V}_{A} / Q=1.0, F_{A}$ is substantially the same as $F_{I}$, but at $\dot{V}_{A} / Q=0.5, F_{A}$ is about $75 \%$ of $F_{I}$. The above equation is inaccurate, however, in that it assumes that inspired ventilation equals expired, and in that it neglects ${ }^{133} \mathrm{Xe}$ recirculating from the periphery (7). Both of these errors tend to bring $F_{A}$ and $F_{I}$ into closer approximation than implied by the equation but significant discrepancies are still present at low $\dot{V}_{A} / \dot{Q}$. Because of these discrepancies, steady-state perfusion indices $\left(Q_{i}\right)$ were computed in addition to the usual perfusion indices (QI):

$$
Q_{\mathrm{i}}=\mathrm{F}_{\mathbf{A}_{\mathrm{i}}} / \mathrm{F}_{\mathbf{I}} \dot{Q}_{\mathbf{I}}
$$

where $F_{A_{i}}$ is regional ${ }^{133} \mathrm{Xe}$ concentration derived from regional $\dot{V}_{A} / \dot{Q}$ and the above steady-state equation. Figures for both $\dot{Q}_{I}$ and $\dot{Q}_{\mathbf{i}}$ will be presented in this communication.

The maximal dose of radiation delivered in the course of the studies was $300 \mathrm{mrad}$ to the lungs and $37 \mathrm{mrad}$ to the rest of the body.

\section{RESULTS}

The MMFR was more depressed than the FEV and was abnormal in all patients (Table I); the degree of abnormality was variable, reflecting relatively mild obstruction of air flow (G.H.) to severe obstruction (G.W.).

Measurements made during ${ }^{133} \mathrm{Xe}$ studies are shown in Table II. The recorded $\tilde{V}$ is the mean of values determined from washout after infusion and after rebreathing. Abnormal $(\tilde{\mathrm{V}}<50)$ and borderline $(50<\tilde{\mathrm{V}}<60)$ regions are shown in bold figures. On the basis of these findings the patients may be separated into three groups. In four patients (D.A., G.H., A.G., and N.T.) the findings were normal, in that $\tilde{V} \geq 60$ in all regions. Four patients (S.W., P.T., K.S., and M.R.) had some regions with normal ${ }^{133} \mathrm{Xe}$ washout and some with borderline or abnormal $\mathrm{V}$ values; the number of regions affected varied from one (K.S.) to six (M.R.). Finally, in two patients (W.A. and G.W.), V was low in all or almost all regions, although the degree of abnormality varied. Regional $\dot{\mathrm{V}} \mathrm{A} / \dot{\mathrm{Q}}$ correlated
TABLE I

Data of Subjects Studied

\begin{tabular}{llccc}
\hline & Sex & Age & MMFR & FEV \\
\hline & & & \% of predicted value \\
D.A. & F & 36 & 55 & 93 \\
G.H. & M & 46 & 63 & 84 \\
A.G. & M & 22 & 56 & 68 \\
N.T. & M & 36 & 41 & 66 \\
S.W.* & M & 32 & 27 & 49 \\
P.T.* & M & 34 & 43 & 67 \\
K.S.* & M & 38 & 55 & 78 \\
M.R.* & F & 51 & 54 & 64 \\
W.A.* & M & 39 & 39 & 65 \\
G.W.* & M & 31 & 7 & 24 \\
\hline
\end{tabular}

MMFR, maximal midexpiratory flow rate; FEV, forced expiratory volume.

* Subject of previous study (2).

with regional $\tilde{\mathrm{V}}$ : depression of one measurement was associated with depression of the other.

When the series as a whole is considered, some regions were involved more frequently than others. As shown in Fig. 1, the lung bases were most commonly affected and the middle zones least commonly, and definitely abnormal values $(\tilde{\mathrm{V}}<50)$ were recorded significantly less of ten $(P<0.05)$ by counter 3 than by any other counter (15).

Regional $\tilde{\mathrm{V}}$ were averaged to determine mean $\tilde{V}$ in each patient, giving an index of over-all ventilatory abnormality as assessed by ${ }^{133} \mathrm{Xe}$. There was significant correlation $(r=0.71$, $P<0.05$ ) between MMFR and mean $\tilde{\mathrm{V}}$ (Fig. 2 ).

The distribution of perfusion was not uniform and was related to the distribution of ventila-

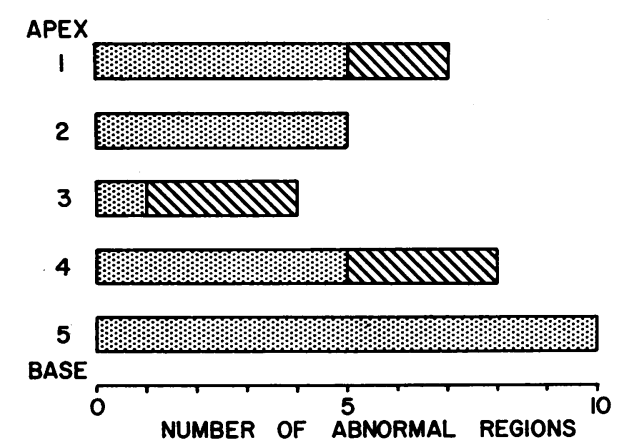

FIGURE 1 Regional incidence of ventilation impairment. Abscissa shows number of regions which were abnormal (strippled) or borderline (hatched). Ordinate shows lung regions from apex to base, designated as counter fields. 


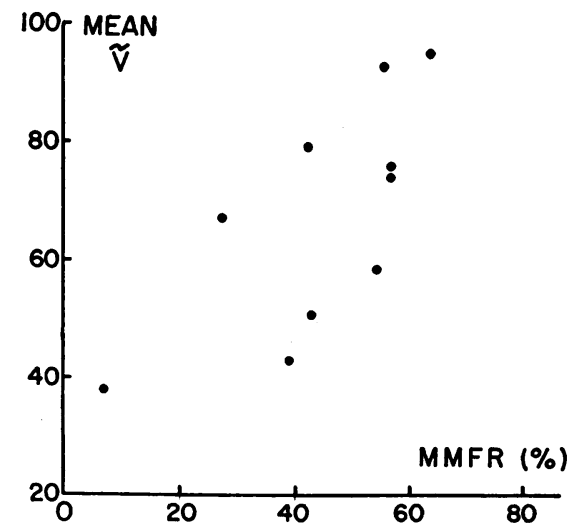

FIGURE 2 Correlation of over-all ventilation assessment by ${ }^{133} \mathrm{Xe}$ with MMFR. Figures for maximal midexpiratory flow rate $(M M F R)$ are percentages of predicted normal values.

tion. If perfusion distribution were dependent upon ventilation distribution, shifts in perfusion from area to area would be determined by the relative degrees of ventilation of the areas involved. Thus, in patient S.W. the borderline $\tilde{V}$ in region $R_{4}$ reflected one of his most severely underventilated regions, which might then be underperfused; by contrast, a similar borderline value $\tilde{V}$ in patient $G . W$. represented this patient's best ventilated region, which might then be overperfused. To take account of this, relative regional ventilation was computed in each patient by comparing individual regional $\tilde{V}$ with the mean $\tilde{V}$ of well-ventilated regions

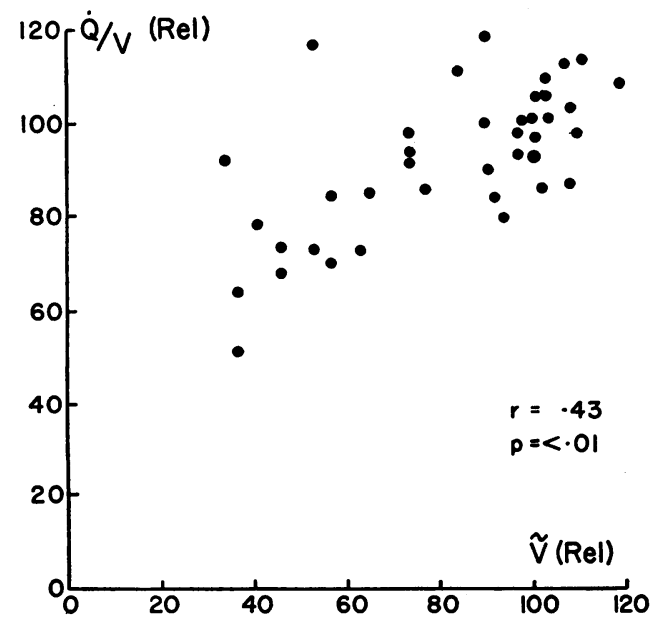

FIGURE 3 Correlation of relative regional blood flow per unit volume $(\dot{Q} / V)$ with relative regional ventilation per unit volume $(\tilde{V})(r=0.43 ; P<0.01)$.
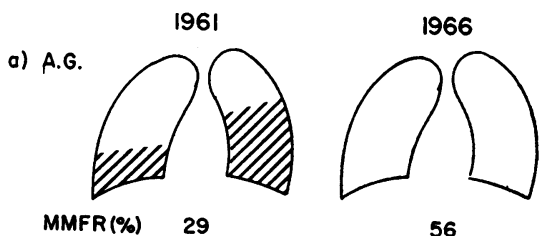

56

b) W.A.
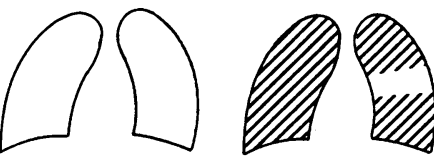

39

c) P. T
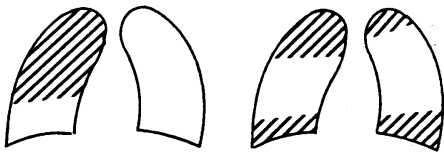

MMFR(\%) 56

43

FIGURE 4 Changes in regional distribution of abnormality of pulmonary function between 1961 and 1966. Regions in which function was abnormal in the three subjects are hatched. Figures for MMFR are percentages of predicted normal values.

$(\tilde{\mathrm{V}}>60)$. Similarly, relative regional perfusion was calculated in each patient by relating regional Q்I to the mean Q்I of normally ventilated regions. In the case of G.W. in whom no region exhibited $\tilde{V}=60$, region $L_{1}(\tilde{V}=59)$ was used as the standard for computation of relative regional ventilation and relative regional perfusion. Use of relative regional ventilation and relative regional perfusion allows inclusion of all patients studied in a single comparison of ventilation distribution with perfusion distribution. The resulting plot is shown in Fig. 3 $(r=0.43$ and $P<0.01)$ : when regional $\tilde{\mathrm{V}}$ was $<70 \%$ of normal, regional perfusion also was decreased. Relative perfusion per unit volume appeared to be independent of $\tilde{V}$ when the latter exceeded $70 \%$ of normal.

Comparison of the results obtained during ${ }^{133} \mathrm{Xe}$ studies with those obtained $5 \mathrm{yr}$ previously (2) showed changes in most cases, generally with parallel change in the MMFR. (Although three counters were used in the first study and five in the second, the total area covered was the same.) During the present study, abnormal ventilation was found in a smaller area of the lungs in three patients (S.W., K.S., and A.G.) and in a greater area in four (P.T., G.W., W.A., and M.R.); only one (N.T.) showed no abnormality on either occasion. Fig. 4 shows 
comparisons of values in three patients. The greatest degree of improvement occurred in A.G. (Fig. $4 \mathrm{a}$ ), and deterioration was most marked in W.A. (Fig. 4 b). Finally, P.T. (Fig. $4 \mathrm{c}$ ) had clearing of one region while others became involved: this patient was the only clearcut example of this phenomenon.

\section{DISCUSSION}

The technique and assumptions involved in the present study have been presented previously (7-9) and are not discussed in detail here. It is necessary to note, however, that "regions" were counter fields and as such frequently did not represent an individual pulmonary lobe or segment. Overlap between counter fields was unavoidable, and the posterior position of the counters made them more sensitive to small areas of abnormality in the posterior part of the chest than to similar areas situated anteriorly. Each value recorded by a counter represented the mean behavior of the lung tissue underlying that counter. Thus, if all units within a counter field had identical degrees of function, the regional measurement would be entirely valid, whereas in a region containing units with varied degrees of function, mean regional measurements might not reflect the true level of function of any single unit. Since the basic regional measurement was the count rate, or amount of isotope, the contribution of a unit or a group of units to the regional measurement was weighted by its relative volume. Thus, difference between regions could have represented admixtures of varied volumes of units with different degrees of function. In such a model, measured interregional differences represent the minimal differences in function that can exist throughout the lung.

Despite these considerations, it is clear that in at least four patients (S.W., P.T., M.R., and K.S.) some lung regions were less well ventilated than others. It is apparent also that the $\dot{V}_{A} / \dot{Q}$ of regions which were relatively hypoventilated were lower than those of better ventilated regions in the same patient. When mixed venous and inspired gas tensions are constant, alveolar and capillary gas tensions are dependent upon local $\dot{\mathrm{V}}_{\mathrm{A}} / \dot{Q}$. When differences in regional or subregional gas tension $\left(\dot{\mathrm{V}}_{\mathrm{A}} / \dot{\mathrm{Q}}\right)$ are large, the efficiency of the lung as a gas exchanging system is decreased. An appropriate estimate of gas exchanging efficiency is the comparison of gas tensions in mixed alveolar gas and arterial blood. Of the respiratory gases, the arterial-alveolar nitrogen difference (a - A) $\mathrm{DN}_{2}$ is most relevant to the present studies, since this value is dependent upon variations in $\dot{V}_{A} / \dot{Q}$ and, in particular, reflects the presence of units with low $\dot{V}_{A} / \dot{Q}$.

Using the data of Table II and the $\mathrm{O}_{2}-\mathrm{CO}_{2}$ diagram of Rahn and Fenn (16), the gaseous composition of mixed alveolar gas and arterial blood many be computed for individual patients, and the resulting $(\mathrm{a}-\mathrm{A}) \mathrm{DN}_{2}$ can be derived. Comparison of these computed values with the measured values in these or comparable patients would be of interest. If measured exceeded calculated $(\mathrm{a}-\mathrm{A}) \mathrm{DN}_{2}$, this value would indicate greater variation in $\dot{\mathrm{V}}_{\mathrm{A}} / \dot{\mathrm{Q}}$ than was measured regionally; i.e., that significant intraregional inhomogeneities of $\dot{V}_{A} / \dot{Q}$ were present. Mean alveolar and arterial nitrogen tensions were calculated from the regional $\dot{\mathrm{V}}_{\mathrm{A}} / \dot{Q}$ and $\dot{Q}_{\mathrm{i}}$ values shown in Table II, and it was assumed that regional volumes were equal. Calculated (A - a) $\mathrm{DN}_{2}$ was $1-2 \mathrm{~mm} \mathrm{Hg}$ in patients S.W., M.R., and P.T. This value represented minimal embarrassment of over-all gas exchange, a smaller $(\mathrm{A}-\mathrm{a}) \mathrm{DN}_{2}$ than that of an erect normal adult subject. We were unable to find reports of measured $(a-\mathrm{A}) \mathrm{DN}_{2}$ in patients comparable to ours. However, (A - a) $\mathrm{DN}_{2}$ may be calculated from data reported by Ledbetter and associates (3), who used an $\mathrm{N}_{2}$ washout technique in their studies of children with asthma. Though expiratory flow rates were not stated, it is noteworthy that the $(\mathrm{A}-\mathrm{a}) \mathrm{DN}_{2}$ was about $2-4 \mathrm{~mm} \mathrm{Hg}$ in the children with the least severe asthma. It is likely that there is a small $(\mathrm{a}-\mathrm{A})$ $\mathrm{DN}_{2}$ in normal recumbent adult subjects due to nonregional inhomogeneities of $\dot{\mathrm{V}}_{\mathrm{A}} / \dot{\mathrm{Q}}$ (17), that would not be detected by ${ }^{133} \mathrm{Xe}$ studies. Thus it is possible that in some of our patients with abnormal lung regions the measured regional $\dot{\mathrm{V}}_{\mathbf{A}} / \dot{Q}$ were accurate representations of gas exchange.

Intraregional homogeneity of function was assessed by regional washout curves. $t_{1}$ was measured twice in each region, once after rebreathing and once after infusion (except, for technical reasons, in patient W.A.). In a region which contains two or more compartments with different $\dot{\mathrm{V}}_{\mathrm{A}} / \dot{Q}$ ratios, the distribution of ${ }^{133} \mathrm{Xe}$ depends 
TABLE II

${ }^{133}$ Xenon Studies of Regional Pulmonary Function

\begin{tabular}{|c|c|c|c|c|c|c|c|c|c|c|c|}
\hline \multirow[b]{2}{*}{ Subject } & \multirow[b]{2}{*}{ Index } & \multicolumn{5}{|c|}{ Left lung } & \multicolumn{5}{|c|}{ Right lung } \\
\hline & & $\begin{array}{c}\text { Apex } \\
\mathrm{L}_{1}\end{array}$ & $\mathrm{~L}_{2}$ & $\mathrm{~L}_{\mathbf{3}}$ & $L_{4}$ & $\begin{array}{c}\text { Base } \\
\mathrm{L}_{6}\end{array}$ & $\begin{array}{c}\text { Apex } \\
\mathbf{R}_{1}\end{array}$ & $\mathbf{R}_{2}$ & $\mathbf{R}_{\mathbf{3}}$ & $\mathbf{R}_{4}$ & $\begin{array}{c}\text { Base } \\
\mathrm{R}_{5}\end{array}$ \\
\hline D.A. & $\begin{array}{l}\dot{V}_{A} / Q \\
\dot{Q} I / \dot{Q}_{i} \\
\tilde{V}\end{array}$ & $\begin{array}{r}0.70 \\
102 / 82 \\
73\end{array}$ & $\begin{array}{r}0.72 \\
105 / 86 \\
74\end{array}$ & $\begin{array}{r}0.75 \\
106 / 87 \\
83\end{array}$ & $\begin{array}{r}0.83 \\
86 / 72 \\
62\end{array}$ & $\begin{array}{r}0.74 \\
104 / 86 \\
67\end{array}$ & $\begin{array}{r}0.70 \\
100 / 82 \\
71\end{array}$ & $\begin{array}{r}0.73 \\
105 / 87 \\
88\end{array}$ & $\begin{array}{r}0.74 \\
99 / 81 \\
73\end{array}$ & $\begin{array}{r}0.75 \\
99 / 81 \\
81\end{array}$ & $\begin{array}{r}0.75 \\
100 / 82 \\
88\end{array}$ \\
\hline G.H. & $\begin{array}{l}\dot{V}_{\mathbf{A}} / \dot{\mathrm{Q}} \\
\dot{\dot{Q}_{1}} / \dot{Q}_{\mathbf{i}} \\
\tilde{V}\end{array}$ & $\begin{array}{r}1.08 \\
102 / 87 \\
100\end{array}$ & $\begin{array}{r}1.09 \\
108 / 92 \\
112\end{array}$ & $\begin{array}{r}1.08 \\
92 / 78 \\
95\end{array}$ & $\begin{array}{r}0.99 \\
9107 / 91 \\
75\end{array}$ & $\begin{array}{r}1.10 \\
113 / 97 \\
104\end{array}$ & $\begin{array}{r}1.12 \\
75 / 65 \\
82\end{array}$ & $\begin{array}{r}1.01 \\
105 / 89 \\
87\end{array}$ & $\begin{array}{r}1.09 \\
97 / 82 \\
72\end{array}$ & $\begin{array}{r}1.10 \\
9 / 85 \\
94\end{array}$ & $\begin{array}{r}1.16 \\
108 / 93 \\
127\end{array}$ \\
\hline A.G. & $\begin{array}{l}\dot{\mathrm{V}} \mathbf{A} / \dot{\mathrm{Q}} \\
\dot{\mathrm{Q}}_{\mathrm{I}} / \dot{Q}_{\mathrm{i}} \\
\tilde{\tilde{V}}\end{array}$ & $\begin{array}{r}0.50 \\
108 / 81 \\
75\end{array}$ & $\begin{array}{r}0.49 \\
106 / 80 \\
70\end{array}$ & $\begin{array}{r}0.52 \\
88 / 67 \\
74\end{array}$ & $\begin{array}{r}0.53 \\
96 / 74 \\
61\end{array}$ & $\begin{array}{r}0.62 \\
86 / 68 \\
76\end{array}$ & $\begin{array}{r}0.47 \\
110 / 81 \\
83\end{array}$ & $\begin{array}{r}0.52 \\
106 / 81 \\
95\end{array}$ & $\begin{array}{r}0.44 \\
108 / 78 \\
63\end{array}$ & $\begin{array}{r}0.52 \\
122 / 93 \\
91\end{array}$ & $\begin{array}{r}0.53 \\
114 / 87 \\
70\end{array}$ \\
\hline N.T. & $\begin{array}{l}\dot{V}_{A} / \dot{Q} \\
Q_{I} / \dot{Q}_{i} \\
\tilde{V}\end{array}$ & $\begin{array}{r}0.69 \\
77 / 63 \\
68\end{array}$ & $\begin{array}{r}0.61 \\
108 / 85 \\
74\end{array}$ & $\begin{array}{r}0.65 \\
117 / 94 \\
74\end{array}$ & $\begin{array}{r}0.61 \\
114 / 90 \\
60\end{array}$ & $\begin{array}{r}0.59 \\
117 / 91 \\
63\end{array}$ & $\begin{array}{r}0.69 \\
73 / 59 \\
70\end{array}$ & $\begin{array}{r}0.69 \\
95 / 77 \\
76\end{array}$ & $\begin{array}{r}0.68 \\
106 / 86 \\
73\end{array}$ & $\begin{array}{r}0.59 \\
112 / 87 \\
65\end{array}$ & $\begin{array}{r}0.67 \\
115 / 93 \\
74\end{array}$ \\
\hline S.W. & $\begin{array}{l}\dot{V}_{\mathrm{A}} / \dot{\mathrm{Q}} \\
\dot{\mathrm{Q}}_{\mathrm{I}} / \dot{\mathrm{Q}}_{\mathrm{i}} \\
\tilde{\tilde{V}}\end{array}$ & $\begin{array}{r}0.68 \\
89 / 72 \\
70\end{array}$ & $\begin{array}{r}0.74 \\
118 / 97 \\
76\end{array}$ & $\begin{array}{r}0.74 \\
108 / 89 \\
79\end{array}$ & $\begin{array}{r}0.60 \\
77 / 60 \\
35\end{array}$ & $\begin{array}{r}0.63 \\
93 / 74 \\
42\end{array}$ & $\begin{array}{r}0.70 \\
125 / 101 \\
82\end{array}$ & $\begin{array}{r}0.76 \\
109 / 90 \\
71\end{array}$ & $\begin{array}{r}0.73 \\
126 / 103 \\
73\end{array}$ & $\begin{array}{r}0.65 \\
96 / 77 \\
58\end{array}$ & $\begin{array}{r}0.74 \\
103 / 84 \\
75\end{array}$ \\
\hline P.T. & $\begin{array}{l}\dot{V}_{A} / \dot{Q} \\
\dot{Q} \mathbf{r} / \dot{Q}_{i} \\
\tilde{\tilde{V}}\end{array}$ & $\begin{array}{r}0.50 \\
70 / 35 \\
38\end{array}$ & $\begin{array}{r}0.50 \\
82 / 62 \\
46\end{array}$ & $\begin{array}{r}0.58 \\
93 / 73 \\
81\end{array}$ & $\begin{array}{r}0.59 \\
115 / 88 \\
61\end{array}$ & $\begin{array}{r}0.50 \\
66 / 50 \\
31\end{array}$ & $\begin{array}{r}0.45 \\
71 / 52 \\
33\end{array}$ & $\begin{array}{r}0.61 \\
83 / 66 \\
71\end{array}$ & $\begin{array}{r}0.68 \\
98 / 79 \\
67\end{array}$ & $\begin{array}{r}0.71 \\
90 / 73 \\
60\end{array}$ & $\begin{array}{r}0.67 \\
49 / 39 \\
25\end{array}$ \\
\hline K.S. & $\begin{array}{l}\dot{V}_{\mathrm{A}} / \dot{Q} \\
\mathrm{Q}_{\mathrm{I}} / \dot{Q}_{\mathrm{i}} \\
\tilde{\tilde{V}}\end{array}$ & $\begin{array}{r}1.07 \\
81 / 76 \\
76\end{array}$ & $\begin{array}{r}1.05 \\
93 / 81 \\
104\end{array}$ & $\begin{array}{r}1.11 \\
100 / 87 \\
117\end{array}$ & $\begin{array}{r}1.17 \\
88 / 78 \\
110\end{array}$ & $\begin{array}{r}1.12 \\
74 / 64 \\
97\end{array}$ & $\begin{array}{r}1.29 \\
78 / 77 \\
107\end{array}$ & $\begin{array}{r}1.15 \\
91 / 80 \\
111\end{array}$ & $\begin{array}{r}1.13 \\
97 / 84 \\
105\end{array}$ & $\begin{array}{r}1.09 \\
64 / 56 \\
64\end{array}$ & $\begin{array}{r}0.91 \\
56 / 48 \\
38\end{array}$ \\
\hline M.R. & $\begin{array}{l}\dot{V}_{A} / \dot{Q} \\
\dot{Q}_{I} / \dot{Q}_{\mathbf{i}} \\
\tilde{\tilde{V}}\end{array}$ & $\begin{array}{r}0.60 \\
109 / 86 \\
62\end{array}$ & $\begin{array}{r}0.68 \\
119 / 96 \\
81\end{array}$ & $\begin{array}{r}0.54 \\
122 / 97 \\
\mathbf{5 7}\end{array}$ & $\begin{array}{r}0.52 \\
127 / 103 \\
36\end{array}$ & $\begin{array}{r}0.46 \\
101 / 74 \\
25\end{array}$ & $\begin{array}{r}0.62 \\
102 / 81 \\
50\end{array}$ & $\begin{array}{r}0.70 \\
98 / 80 \\
63\end{array}$ & $\begin{array}{r}0.65 \\
110 / 88 \\
69\end{array}$ & $\begin{array}{r}0.63 \\
107 / 85 \\
52\end{array}$ & $\begin{array}{r}0.54 \\
86 / 66 \\
29\end{array}$ \\
\hline W.A. & $\begin{array}{l}\dot{V}_{A} / \dot{Q} \\
\dot{Q}_{1} / \dot{Q}_{\mathbf{i}} \\
\tilde{V}^{*}\end{array}$ & $\begin{array}{c}0.52 \\
\text { NS } \\
34\end{array}$ & $\begin{array}{l}0.60 \\
\text { NS } \\
39\end{array}$ & $\begin{array}{c}0.82 \\
\text { NS } \\
61\end{array}$ & $\begin{array}{c}0.78 \\
\mathrm{NS} \\
50\end{array}$ & $\begin{array}{c}0.65 \\
\text { NS } \\
47\end{array}$ & $\begin{array}{c}0.66 \\
\text { NS } \\
40\end{array}$ & $\begin{array}{c}0.64 \\
\text { NS } \\
39\end{array}$ & $\begin{array}{c}0.65 \\
\mathrm{NS} \\
50\end{array}$ & $\begin{array}{c}0.63 \\
\text { NS } \\
38\end{array}$ & $\begin{array}{c}0.54 \\
\text { NS } \\
37\end{array}$ \\
\hline G.W. & $\begin{array}{l}\dot{V}_{\mathrm{A}} / \dot{\mathrm{Q}} \\
\dot{\mathrm{Q}}_{\mathrm{I}} / \dot{Q}_{\mathrm{i}} \\
\tilde{\tilde{V}}\end{array}$ & $\begin{array}{r}0.72 \\
73 / 60 \\
59\end{array}$ & $\begin{array}{r}0.68 \\
62 / 50 \\
34\end{array}$ & $\begin{array}{r}0.73 \\
64 / 53 \\
52\end{array}$ & $\begin{array}{c}0.65 \\
69 / 55 \\
37\end{array}$ & $\begin{array}{r}0.57 \\
66 / 51 \\
26\end{array}$ & $\begin{array}{r}0.67 \\
72 / 58 \\
39\end{array}$ & $\begin{array}{c}0.65 \\
66 / 53 \\
30\end{array}$ & $\begin{array}{r}0.66 \\
70 / 56 \\
35\end{array}$ & $\begin{array}{r}0.66 \\
67 / 54 \\
29\end{array}$ & $\begin{array}{r}0.68 \\
59 / 48 \\
35\end{array}$ \\
\hline
\end{tabular}

NS, not studied.

Bold figures indicate abnormally low or borderline values.

* Values represent washout after infusion only.

upon the method of administration of the isotope. When it is infused, units with low $\dot{\mathrm{V}}_{\mathrm{A}} / \dot{Q}$ have relatively high ${ }^{133} \mathrm{Xe}$ concentrations and count rates, whereas the reverse is true when the isotope is inspired. Thus, washout after infusion yields values that tend to reflect compartments with low $\dot{\mathrm{V}}_{\mathbf{A}} / \dot{\mathrm{Q}}$ and washout after rebreathing reflects those with high $\dot{\mathrm{V}}_{\mathbf{A}} / \dot{Q}$. If these compartments did not have the same ventilation per unit volume, the $t_{\frac{1}{2}}$ after infusion would differ from that after rebreath- ing. As shown in Fig. 5, such washout discrepancies were not apparent in the present series; no intra-regional heterogeneity of function was indicated. More sophisticated analysis of regional washout might reveal inhomogeneities of regional function; however, rigorous analysis of regional washout is not accurate (10).

Despite these difficulties, quantitative interpretation of regional $\tilde{\mathrm{V}}$ can be attempted in two cases (W.A. and G.W.). These patients had grossly 


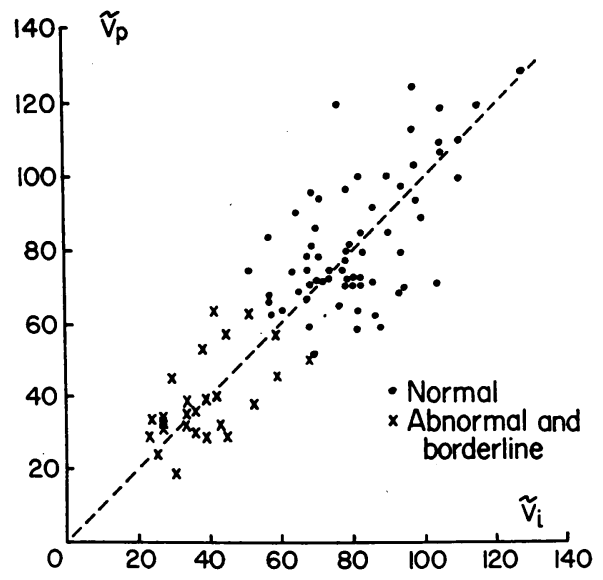

FIGURE 5 Comparison of regional washout of infused ${ }^{133} \mathrm{Xe}\left(\tilde{V}_{p}\right)$ and inspired ${ }^{133} \mathrm{Xe}\left(\tilde{V}_{i}\right)$. Dotted line is line of identity. Figures for $\dot{V}_{i}$ were not obtained for W.A., so the number of abnormal regions is less than in Fig. 1.

decreased $\tilde{V}$ in virtually all lung regions, decreases too large to be accounted for by the factors detailed by Matthews and Dollery (10). If the regional washouts had reflected the state of all of the lung units, the only possible explanation for the gross prolongation of all of the regional washouts would have been that these patients either were not ventilating adequately or had extraordinarily large FRC. Since neither was the case, regional washouts did not reflect the state of all lung units. Therefore, relatively well-ventilated units, although not detected in these studies, must have existed; presumably such units had high $\dot{V}_{A} / \dot{Q}$. Since these well-ventilated units had no regional representation, and since $t_{1}$ after rebreathing and after infusion were similar in G.W., it is likely that these units were relatively evenly distributed throughout the lungs and amounted to a small volume.

Regions with decreased ventilation were underperfused (Fig. 3). This underperfusion was not entirely effective from a gas exchange point of view since $\dot{\mathrm{V}}_{\mathrm{A}} / \dot{Q}$ was relatively low in hypoventilated regions; if there had been no change in perfusion distribution, however, over-all gas exchange obviously would have been more inefficient. The normal blood flow distribution found in patients with asthma in a previous study (2) probably was due to their upright posture; since blood flow distribution in the erect normal subject is uneven (9), abnormalities are difficult to detect. Since it is likely that the lung parenchyma was morphologically normal in these patients, regional decreases in flow probably were functional in origin. This hypothesis is supported by the findings of Woolcock, McRae, Morris, and Read (18), who showed that abnormalities of blood flow distribution may occur temporarily during exacerbations of asthma. Hypoventilated regions have low $\dot{V}_{\mathrm{A}} / \dot{Q}$ and, therefore, have relatively low oxygen tension $\left(\mathrm{Po}_{2}\right)$, and, since alveolar hypoxia is a known pressor agent for the pulmonary circulation (19), regional hypoxic vasoconstriction may divert flow from hypoventilated regions. This hypothesis does not explain the severe degree of underperfusion of the right lung base in patient K.S.; though the $\dot{V}_{A} / \dot{Q}$ was lower in the hypoventilated region than elsewhere in the lung, the over-all $\dot{\mathrm{V}} \mathrm{A} / \dot{Q}$ was high, and the hypoventilated, underperfused region may have had $\mathrm{a}^{\mathrm{Po}_{2}}$ of about $100 \mathrm{~mm} \mathrm{Hg}$. This value is considerably higher than that which has been shown to influence hemodynamics (19).

The positive correlation between MMFR and the over-all ventilatory impairment is of interest. Theoretically, there is no need for such correlation, regional washouts being more analogous to tests involving inert gas washout or washin. It is apparent that both MMFR and regional washouts are sensitive to the regional and over-all increases in airway resistance that presumably constitute the major physiologic pulmonary abnormality in asthma. The correlation between mean $\tilde{\mathrm{V}}$ and MMFR (Fig. 2) would be greater if N.T. and S.W. were excluded: these patients had lower MMFR values than might be expected on the basis of their mean $\tilde{\mathrm{V}}$. These patients also had unusually slow, regular breathing patterns, with a frequency of 3 breaths/min in S.W. and $5-6$ breaths/min in N.T. Such low respiratory frequencies could result in normal values by ${ }^{133} \mathrm{Xe}$ testing, by minimizing inequalities in ventilation distribution that were due to inequalities in regional time constants (regional resistance $\times$ regional compliance).

The four subjects who showed no abnormality of regional lung function had reduced MMFR and, therefore, some degree of airway obstruction. This finding could mean that the obstruction was of similar, mild degree throughout the lungs. Since ${ }^{133} \mathrm{Xe}$ methods are more sensitive to interregional differences in function than to deviations from "absolute normal," evenly distributed minor abnormalities of function could go undetected. 
If the present small series may be taken as a representative cross-section of patients with asthma, a sequence-is suggested. A relatively mild degree of obstruction (MMFR $>50 \%$ predicted) tends to be distributed evenly throughout the lungs. Progression of the condition appears to be uneven, resulting in greater degrees of obstruction in some regions than in others and greater decreases in function in the regions most affected. Fig. 1 indicates that there may be a regional sequence of involvement, function deteriorating most often, and perhaps earliest, at the lung bases, and then at the apices, with a tendency for the middle zones to be spared; however, the findings shown in Fig. $4 \mathrm{c}$ suggest that a sequence may change with time. As implied above, severe airway obstruction involves all lung zones though to different degrees in different regions. Although the reasons for these findings are not apparent, the findings themselves may be important for consideration of the pathogenesis of asthma.

\section{ACKNOWLEDGMENTS}

The authors gratefully acknowledge the technical assistance of Mr. W. R. D. Ross and Miss J. Doman.

This work was supported in part by grants from the Medical Research Council of Canada and The John A. Hartford Foundation, Inc., of the U. S. A.

\section{REFERENCES}

1. Beale, H. D., W. S. Fowler, and J. H. Comroe, Jr. 1962. Pulmonary function studies in 20 asthmatic patients in the symptom-free interval. J. Allergy. 23: 1.

2. Bentivoglio, L. G., F. Beerel, A. C. Bryan, P. B. Stewart, B. Rose, and D. V. Bates. 1963. Regional pulmonary function studied with xenon ${ }^{138}$ in patients with bronchial asthma. J. Clin. Invest. $42: 1193$.

3. Ledbetter, M. K., E. Bruck, and L. E. Farhi. 1964. Perfusion of the underventilated compartment of the lungs in asthmatic children. J. Clin. Invest. 43: 2233.

4. Bates, D. V., and R. V. Christie. 1964. Respiratory Function in Disease. W. B. Saunders Co., Philadelphia. 8.

4 a. Bates, D. V., and R. V. Christie. 1964. Respiratory Function in Disease. W. B. Saunders Co., Philadelphia. 92.
5. Sekelj, P., and M. McGregor. 1967. Estimation of cardiac output in man using an ear oximeter and Coomassie blue dye. IRE Inst. Radio Engrs. Trans. Bio-med. Electron. 8: 127.

6. McGregor, M., P. Sekelj, and W. Adam. 1961. Measurement of cardiac output in man by dye dilution curves using simultaneous ear oximeter and whole blood cuvette techniques. Circulation Res. 9: 1083.

7. Anthonisen, N. R., M. B. Dolovich, and D. V. Bates. 1966. Steady state measurement of regional ventilation to perfusion ratios in normal man. J. Clin. Invest. 45: 1349.

8. Bass, H., T. Hecksher, and N. R. Anthonisen. 1967. Regional pulmonary gas exchange in patients with pulmonary embolism. Clin Sci. 33: 355.

9. Ball, W. C., Jr., P. B. Stewart, L. G. S. Newsham, and D. V. Bates. 1962. Regional pulmonary function studied with xenon ${ }^{133}$. J. Clin. Invest. 41: 519.

10. Matthews, C. M. E., and C. T. Dollery. 1965. Interpretation of ${ }^{133} \mathrm{Xe}$ lung wash-in and wash-out curves, using an analogue computer. Clin. Sci. 28: 573.

11. Stead, E. A., Jr., J. V. Warren, A. J. Merrill, and E. S. Brannon. 1945. The cardiac output in male subjects as measured by the technique of right atrial catheterization. Normal values with observations on the effect of anxiety and tilting. J. Clin. Invest. 24: 326.

12. Anthonisen, N. R., D. Bartlett, and S. M. Tenney. 1965. Postural effect on ventilatory control. J. Appl. Physiol. 20: 191.

13. Handbook of Physiology. W. O. Fenn and H. Rahn, editors. American Physiological Society, Washington, D. C. 1964. 1: 740.

14. Yeh, S.-Y., and R. E. Peterson. 1965. Solubility of krypton and xenon in blood, protein solutions, and tissue homogenates. J. Appl. Physiol. 20: 1041.

15. Mainland, D. 1963. Elementary Medical Statistics. W. B. Saunders Co., Philadelphia. 2nd edition. 358.

16. Rahn, H., and W. O. Fenn 1955. A Graphical Analysis of the Respiratory Gas Exchange. The $\mathrm{O}_{2}-\mathrm{CO}_{2}$ Diagram. American Physiological Society, Washington, D. C.

17. Lenfant, C. 1963. Measurement of ventilation/perfusion distribution with alveolar-arterial differences. J. Appl. Physiol. 18: 1090.

18. Woolcock, A. J., J. McRae, J. G. Morris, and J. Read. 1966. Abnormal pulmonary blood flow distribution in bronchial asthma. Australasian Ann. Med. 15: 196.

19. Fishman, A. P. 1961. Respirataory gases in the regulation of the pulmonary circulation. Physiol. Rev. 41: 214 . 